\title{
Health care coverage among long-distance truckers in India: an evaluation based on the Tanahashi model
}

This article was published in the following Dove Press journal:

HIVIAIDS - Research and Palliative Care

23 March 2015

Number of times this article has been viewed

\author{
Varun Sharma' \\ Niranjan Saggurti ${ }^{2}$ \\ Shalini Bharat' \\ 'School of Health Systems Studies, \\ Tata Institute of Social Sciences, \\ Mumbai, India; ${ }^{2}$ HIV AIDS Program, \\ Population Council, New Delhi, India
}

\begin{abstract}
Long-distance truckers (LDTDs) are vulnerable to human immunodeficiency virus infection and other sexually transmitted infections due to the nature of their work, working environment, and frequent mobility. This paper examines and comments on the health care coverage provisioned under "Kavach" Project. Data from the Integrated Behavioural and Biological Survey, National Highway gathered from 2,066 LDTDs in Round 1 and 2,085 LDTDs in Round 2, who traveled in four extreme road corridors travelled by LDTDs in India, were used for analysis. Analysis reveals that service capacity in terms of socially marketed condoms per thousand LDTDs has increased from Round 1 to Round 2 (4,430 to 6,876, respectively). Accessibility coverage in terms of knowledge about the Khushi clinic has significantly decreased between Rounds 1 and $2(60.9 \%$ to $54.6 \% ; P<0.001)$. Acceptability coverage has increased between the two rounds $(13.8 \%$ to $50.6 \% ; P<0.001)$. Contact coverage has also increased between the rounds $(12.7 \%$ to $22.3 \% ; P<0.001)$. Effectiveness coverage for preventive and curative care has also increased significantly. This paper comments on the gaps in accessibility and acceptability of health care coverage and emphasizes the need for further studies to assess the contextual factors that influence the effectiveness and efficiency of interventions designed to address access barriers and to identify what combination of interventions may generate the best possible outcome.
\end{abstract}

Keywords: HIV, long-distance truck drivers, mobility, national highways, Tanahashi framework, India

\section{Introduction}

Workers in the transport sector are vulnerable to human immunodeficiency virus (HIV) infection and other sexually transmitted infections (STIs) due to the nature of their occupation, difficult work environment, and poor economic and living conditions. ${ }^{1}$ Studies have reported the spread of HIV along major truck routes, and the crucial role played by long-distance truckers (LDTDs) (LDTDs include truck drivers and their helpers traveling $800 \mathrm{~km}$ or more in a single direction) in carrying HIV infection from one place to another and transmitting infection from high-risk populations (high-risk population includes female sex workers, men who have sex with men, and injecting drug users) to low-risk populations (low-risk population primarily includes spouses of migrant/mobile population). ${ }^{2-4}$ Multiple sex partners, ignorance about the use of condoms, and inconsistent or no condom use during sexual acts are commonly reported behavior patterns among LDTDs. ${ }^{5-9}$ In addition, LDTDs lack complete and correct information about HIV and other STIs, resulting in low self-perceived risk of HIV infection and other STIs. ${ }^{10-12}$
Correspondence: Varun Sharma School of Health Systems Studies, Tata Institute of Social Sciences, V N Purav Marg, Deonar, Mumbai 400088, Maharashtra, India

$\mathrm{Tel}+9 \mid 988046$ I550

$\mathrm{Fax}+912225525060$

Email sharmavarun84@gmail.com 
Due to frequent mobility, LDTDs lack access to general health care, and low contact with HIV intervention programs restricts their demand in seeking health care in general and sexual and reproductive health care in particular. ${ }^{13-15}$ Labeling of truck drivers as a high-risk group has marginalized them socially, thus affecting their willingness to access sexual and reproductive health services, and accordingly, their health needs remain uncared for. ${ }^{16-18}$ Intensive exposure to interventions may promote better access to health care, leading to safer sexual behavior and limiting the incidence of STIs and HIV infection. ${ }^{5,6,15}$ Various studies have reiterated the need for focused interventions among this group, such as intensive engagements, community mobilization, social vaccine (involves disseminating information and awareness regarding safer sexual behavior, $100 \%$ condom use, and behavior change communication), and non-governmental organization sector facilitations. ${ }^{6,19-21}$

There are approximately 5-6 million truck drivers and their helpers in India. ${ }^{22}$ Of these, almost, 3-3.5 million are LDTDs and of them, nearly a third (36\%) are clients of commercial sex workers. ${ }^{3,23,24}$ HIV prevalence among truckers in India is more than $1 \%(1.48 \%) .{ }^{25}$ Moreover, a high HIV prevalence is reported among antenatal clinic attendees whose spouses are truck drivers/helpers $(1.14 \%$ and $0.74 \%$ in urban and rural India, respectively) ${ }^{25}$ High HIV prevalence is also reported among STI patients who are truck drivers (3.6\% and 5.9\% in urban and rural areas, respectively). ${ }^{25}$ Nationally, a variety of interventions have been initiated to reduce HIV prevalence among this group. The United Kingdom Department for International Development (DFID) commissioned the "Healthy Highways" program in 1995 as a consolidated national program, which was launched in 1996 across 200 sites spread over 19 states in India. ${ }^{5,26}$ The intervention sites were either trans-shipment locations (TSLs) or roadside cafes along the highway. ${ }^{26}$ Likewise, in the late 1990s, the Bhoruka Public Welfare Trust established "free tea parlors" at major truck halt points where truckers were encouraged to utilize STI clinic services. ${ }^{5}$ The major focus of these programs and interventions has been promotion of consistent condom use and behavior change communication among this vulnerable group. ${ }^{26,27}$

The success or failure of any health care intervention depends on various demand- and supply-side factors. The success of a health care service or intervention is measured by the ability of the service to interact with the people that it covers (target population), and to successfully convert intention into action to make the intervention truly successful. ${ }^{28}$ Therefore, it is important for the executing organizations/ agencies/government to pay attention to the entire process of access to health care to ensure an effective service delivery to vulnerable groups. ${ }^{29}$

In this paper, an attempt is made to investigate various stages of health care coverage, health care provisions/ entitlements, and use of health care services/benefits by LDTDs, with reference to the structure inferred by Tanahashi (1978). Given the framework of health care coverage and its evaluation, ${ }^{28}$ the paper comments on the gaps/bottlenecks (demand- and supply-side) that may have influenced the ease of use/access to health care services, provisioned under the Kavach project funded by the Bill and Melinda Gates Foundation (BMGF) under the Avahan India AIDS (acquired immunodeficiency syndrome) Initiative. ${ }^{26}$

\section{Access to health care coverage}

Access to health care coverage is a complex concept to characterize. It includes different dimensions of effective service delivery, extending from the availability to an effective utilization of service by the target population. If health services are to be utilized, they must be available, accessible, and affordable. Tanahashi mentioned different stages for the measurement of health care coverage, which are vital conditions for provisioning the service. Assessment of the coverage can enable health system management to recognize the issues in the operation of the services, to analyze the constraining components for these issues, and to select measures for service improvement. Tanahashi described five coverage or access issues that encourage/hinder an individual's use of health care services (availability, accessibility, acceptability, contact, and effectiveness coverage). ${ }^{28}$

Availability coverage refers to the availability of a service to cover the health needs of the target group measured either in terms of the infrastructure or availability of manpower, drugs, and supplies. It measures the service capacity. The health services should be located within a reasonable reach of the people, ie, physical location of the health facility. Location of service defines the accessibility coverage. Once accessibility is ensured, service usage is assessed by the number of individuals who are willing to use it, ie, the service should be acceptable in the socioeconomic and cultural setup of the target community. Contact coverage estimates the number of individuals in the target population who have reached the facility at their time of requirement. Effectiveness coverage measures the proportion of the target population that has actually used the services. This coverage assesses the effectiveness of the intervention in providing a valid solution/ valid treatment for the target population. ${ }^{28}$

Using the above analytical framework, an attempt is made in this paper to assess the health care coverage of Khushi 
clinics among LDTDs. Khushi clinics were established at identified trans-shipment sites to provide LDTDs access to promotive, preventive, and curative services to meet their health needs. ${ }^{30}$

\section{Kavach project-Khushi clinics}

With the support of the Avahan India AIDS initiative of BMGF, Transport Corporation of India Foundation (TCIF) launched project Kavach (Kavach means "shield") in 2003. The project was aimed at reaching the maximum number of LDTDs in the four main corridors to reduce the spread of HIV and other STIs among the mobile truckers. ${ }^{30,31}$ The project provided promotive, preventive, and clinical services through Khushi clinics (Khushi means "happiness") located at 17 major truckers' halt points (total numbers of clinics have been reduced lately) in nine states in India., ${ }^{5,31}$ The Kavach project was initiated at 36 TSLs in India covering major national highways in four corridors, ie, the North-West (NW), North-East (NE), North-South (NS), and South-East (SE) corridors. However, program monitoring data in the first 18 months showed low service utilization by the truckers. Hence, the program was redesigned in 2006 by selecting 17 (15 TSLs and two check posts) for intensive intervention. ${ }^{26}$ Among these Khushi clinics, Sanjay Gandhi Transport Nagar, Delhi, intercepts LDTDs plying on the NE, NW, and NS corridors; Ghaziabad Transport Nagar, Uttar Pradesh, intercepts truckers plying on the NE, NW, and NS routes; and Neelamangala, Bangalore, intercepts truckers plying on the SE and NS routes. Apart from these intercepting junctions, there were five other clinics established on the NE route (Agra, Kanpur, Varanasi, Jamshedpur, and Dhanbad); four on the NW route (Jaipur transport Nagar in Jaipur, Kalamboli in Mumbai, Nigdi in Pune and Hubali/ Dharwad in Karnataka); three on the SE route (Ichachapuram, Andhra Pradesh; Hyderabad Autonagar, Andhra Pradesh; and Jamsola, Orissa); and two along the NS corridor (Nagpur Pardi with a satellite clinic at Wadi, Maharashtra, and Indore, Madhya Pradesh, respectively). On average, there is a distance of 200-600 km between any two Khushi clinics on the specified corridors. Assuming that the LDTD travels more than $800 \mathrm{~km}$ one way (by definition), it may be argued that he may have come across at least one Khushi clinic during the trip. Various events, programs, and sets of interventions (eg, nukkad natak or street corner plays, film shows, exhibitions, Seena Taan ke (bravery award) Bahaduri Puraskar and truckers' utsav (truckers' festival), free consultation, social marketing of condoms, various outreach activities, peer educators, etc) were launched under the intervention. The intervention aimed at raising self-esteem among LDTDs through commu- nication, eg, trained outreach workers accepting a lift along the highways to discuss general health and raise awareness regarding Khushi clinics; promoting safer sexual conduct, eg, promoting consistent condom use and counseling; and positioning Khushi clinics as solution providers, eg, as health clinics for all LDTDs' health needs. ${ }^{30}$

\section{Material and methods}

The data used to assess the health care coverage at Khushi clinics under the Tanahashi analytical framework were drawn from two rounds of Integrated Behavioural and Biological Assessment, National Highway (IBBA-NH) survey. The IBBA-NH survey was conducted on the four defined route categories NE, NS, NW, and SE, where the Avahan program operated. The route categories were the extreme road corridors travelled by LDTDs.

\section{Survey sites}

TSLs were selected as study locales. In Round 1, seven trans-shipment areas (Sanjay Gandhi Transport Nagar (SGTN), New Delhi; Ghaziabad Transport Nagar, Uttar Pradesh; Kalamboli, Mumbai; Narol Chowkdi, Ahmedabad; Gandhidham, Kandla; Neelamangala, Bangalore; and Territy bazar, Kolkata) and in Round 2, six trans-shipment areas (except Kandala) were selected. In the second round of the survey, Kandala was dropped as only 46 interviews had been conducted in Round 1 , and it was not logistically and technically efficient to conduct a survey there again. ${ }^{31}$

\section{Respondents}

LDTDs were the respondents in both rounds of the survey. An LDTD was defined as a trucker who takes a consignment from one place to another destination located along the national highways and who travels more than $800 \mathrm{~km}$ one-way before returning back to the place of origin.

\section{Sample size estimation}

Two stage time, location cluster sampling approach in which trans-shipment establishments as primary sampling unit (PSU) and truck drivers as the secondary sampling unit was used, to draw a representative sample in both rounds. PSU in IBBA-NH had both a location as well as time dimension. The location dimension was taken as trans-shipment establishments and the time dimension was taken as 1 day (ie, 24 hours). The PSUs were selected at the first stage by probability proportional to size methodology followed by random selection of LDTDs (the respondents of the study) in the second stage. A total of 2,066 LDTDs in Round 1 and 2,085 LDTDs in Round 2 were interviewed. ${ }^{31}$ The data were 
collected from June 2007 to September 2007 for Round 1 and from September 2009 to January 2010 for Round 2. Detailed methodology is explained elsewhere. ${ }^{31}$

\section{Data instruments}

Data were collected from a well-designed, structured interview schedule in both rounds of the survey. Information related to socio-demographic profiles of LDTDs, work and mobility, sexual behavior with different sex partners, knowledge about HIV and other STIs, and exposure to interventions were collected. In addition, behavioural aspects for biological assessment, and blood and urine samples of consenting LDTDs were collected for estimating the prevalence of HIV and other STIs.

\section{Ethical approval}

Clearance for the IBBA-NH survey was obtained from the Health Ministry Screening Committee (HMSC), Government of India. The IBBA-NH protocol was approved by the Scientific Advisory Committee (SAC) of the National AIDS Research Institute (NARI) and the Protection of Human Subjects Committee (PHSC) of Family Health International (FHI). Ethical approval for IBBA-NH was obtained from Scientific Advisory Committee (SAC) of the National Institute of Medical Science (NIMS), which had additionally reviewed and approved the protocol, consent forms, study instruments, standard operating procedures, and field manuals. $^{31}$

\section{Framework for analysis}

With the given information set and the flexibility in the definition of coverage, according to the Tanahashi framework for health care coverage, ${ }^{28}$ a matrix (Table 1 ) was used to characterize the indicators used as a part of this paper. The Tanahashi framework explains five coverages and indicators, which define service delivery and access to health care coverage. Without the program information, it is difficult to measure service capacity and availability coverage. For the purpose of this paper, it is assumed that the service is available for all LDTDs involved in the IBBA-NH survey (as the intervention was expected to reach about 1.4 million truckers). However, an attempt is made to estimate only a few indicators of service capacity, given the aggregate data in the published literature related to the intervention. With the limited information in the IBBA-NH survey, accessibility coverage is difficult to measure in terms of physical location of the health care service. Accessibility coverage is characterized as "accessibility of information," which may influence usage considerably. It is assumed that LDTDs who have known about Khushi clinic and seen the logo of the Khushi clinic, are aware of the services provided in the clinic, and can access the services. As referred to in various studies, lower levels of awareness may have implications for access to care, and may impact equitable access to services. ${ }^{32,33}$ Accordingly, awareness and knowledge may be viewed as a fair indicator of accessibility. In the process of service provisioning, association with the Khushi clinic is considered to be an indicator of acceptability. The individuals who have known about the clinic for more than or equal to 6 months are assumed to be connected with the activities of the clinic and hence, fairly accepting of clinic activities. To measure the contact coverage, visits to Khushi clinic (including a visit to the doctor at the clinic, a visit for general ailments, and a visit for STI) are taken as an indicator. The individuals who have gone to the Khushi clinic for any purpose are expected to have effective contact coverage. For effectiveness coverage, two separate measures were used to quantify: 1) preventive and 2) curative care. As the intervention focused on promotive, preventive, and curative care, it bodes well for assessing the effectiveness coverage based on these two measurements. Both responses (spontaneous and aided) in the IBBA-NH survey are used while estimating this coverage. To estimate the different coverage in both rounds, total number of LDTDs interviewed in each round was taken as the denominator.

\section{Statistical analysis}

Bivariate analysis was used to assess the change in different coverage indicators, to evaluate the impact of intervention. A pooled information set (from Round 1 and Round 2) was generated with required variables from the IBBA-NH survey. Data were presented in percentages/proportions with respect to a base indicator. The chi-square $\left(\chi^{2}\right)$ test was used to check the statistical strength of the analysis at a $95 \%$ confidence interval. Sampling weights were applied accordingly to correct for unequal probabilities of selection. ${ }^{31}$ All the analyses were carried out using SPSS version 20 (IBM Corporation, Armonk, NY, USA).

\section{Results}

It is assumed that each of the LDTDs who responded to the IBBA-NH survey could avail themselves of the services available under the Kavach project. Hence, availability coverage is assumed to be $100 \%$ in both rounds. However, to estimate the correct and actual nature of service capacity, program data are needed. Information extracted from available literature and Avahan centralized management information system (CMIS) data provides a glimpse of service capacity under the intervention in both rounds of analysis. ${ }^{34}$ Socially 
Table I A framework for analysis of access to health care coverage under the Kavach Project, a part of the Avahan India initiative funded by the BMGF

\begin{tabular}{|c|c|c|}
\hline Type of access/coverage & Definition & Effectiveness indicators \\
\hline $\begin{array}{l}\text { Availability coverage } \\
\text { (service capacity)* }\end{array}$ & $\begin{array}{l}\text { Resources required and availability of those } \\
\text { resources to provide a service, limits the } \\
\text { maximum capacity of the service. The degree } \\
\text { of this capacity to the target populace is } \\
\text { known as service capacity. }\end{array}$ & $\begin{array}{l}\text { Sites/clinic per 100,000 estimated beneficiaries } \\
\text { Condoms per thousand estimated beneficiaries }\end{array}$ \\
\hline Accessibility coverage & $\begin{array}{l}\text { Services should be located within a } \\
\text { reasonable reach of the people who might } \\
\text { benefit from them. In this context capacity } \\
\text { of the service is constrained by the number } \\
\text { of individuals who can reach and use the } \\
\text { service. }\end{array}$ & $\begin{array}{l}\text { \% of total LDTDs interviewed during IBBA-NH who had either } \\
\text { heard of or seen the logo of Khushi clinic: } \\
\text { - \% of total LDTDs interviewed during IBBA-NH who had heard } \\
\text { about Khushi clinic } \\
\text { \% of total LDTDs interviewed during IBBA-NH who had seen the } \\
\text { logo of Khushi clinic }\end{array}$ \\
\hline Acceptability coverage & $\begin{array}{l}\text { Service should be acceptable in the given } \\
\text { societal and cultural norms. In this context, } \\
\text { the capacity of the service is limited by the } \\
\text { number of individuals who are willing to } \\
\text { use accessible services. }\end{array}$ & $\begin{array}{l}\text { - \% of total LDTDs interviewed, who had associated with Khushi } \\
\text { clinic for more than or equal to } 6 \text { months } \\
\text { - \% of LDTDs who had heard about/seen the logo of Khushi clinic } \\
\text { and who had associated with it for more than or equal to } 6 \text { months }\end{array}$ \\
\hline Contact coverage & $\begin{array}{l}\text { This stage in the process of service provision } \\
\text { is a measurement of service output and is } \\
\text { the ratio of actual users to target population. }\end{array}$ & $\begin{array}{l}\text { - \% of total LDTDs interviewed who had visited a doctor at Khushi } \\
\text { clinic } \\
\text { - \% of LDTDs who had heard about/seen the logo of Khushi clinic } \\
\text { and had visited a doctor at Khushi clinic } \\
\text { - \% of total LDTDs interviewed who had visited for general ailments } \\
\text { - \% of LDTDs who had heard about/seen the logo of Khushi clinic } \\
\text { and visited for general ailments } \\
\text { - \% of total LDTDs who had visited for STI } \\
\text { - \% of LDTDs who had heard about/seen the logo of Khushi clinic } \\
\text { and visited for STI }\end{array}$ \\
\hline Effectiveness coverage & $\begin{array}{l}\text { At this stage of service provision, service } \\
\text { performance is evaluated. The number of } \\
\text { individuals who have received satisfactory } \\
\text { services is in this way an effective } \\
\text { measurement of service output. }\end{array}$ & $\begin{array}{l}\text { Preventive } \\
\text { - \% of total LDTDs who received a health card } \\
\text { - \% of LDTDs who had heard about/seen the logo of Khushi clinic } \\
\text { and had their own health card } \\
\text { - \% of total LDTDs who received counseling } \\
\text { - \% of LDTDs who had heard about/seen the logo of Khushi clinic } \\
\text { and received counseling } \\
\text { - \% of total LDTDs who received condoms } \\
\text { - \% of LDTDs who had heard about/seen the logo of Khushi clinic } \\
\text { and received condoms } \\
\text { - \% of total LDTDs who received referrals for other health facilities } \\
\text { - \% of LDTDs who had heard about/seen the logo of Khushi clinic } \\
\text { and received a referral for other health facilities } \\
\text { - \% of total LDTDs who took part in the meeting conducted by } \\
\text { Khushi clinics for LDTDs regarding their health issues or any } \\
\text { entertainment program } \\
\text { - \% of LDTDs who had heard about/seen the logo of Khushi clinic } \\
\text { and took part in the meeting conducted by Khushi clinics for } \\
\text { LDTDs regarding their health issues or any entertainment program } \\
\text { Curative } \\
\text { - \% of total LDTDs who sought advice/medicine from Khushi clinic } \\
\text { - \% of LDTDs who had heard about/seen the logo of Khushi clinic } \\
\text { and sought advice/medicine from Khushi clinic }\end{array}$ \\
\hline
\end{tabular}

Note: *Aggregate-level data will be required to estimate the ratio between the capacity and target population.

Abbreviations: BMGF, the Bill \& Melinda Gates Foundation; LDTDs, long-distance truckers; IBBA-NH, Integrated Behavioural and Biological Assessment, National Highway; STI, sexually transmitted infection.

marketed number of condoms per thousand targeted beneficiaries increased from Round 1 to Round 2 (4,430 to 6,876, respectively). However, the number of sites per 100,000 beneficiaries diminished from six to four between Round 1 and Round 2, respectively. Table 2 provides the indicators of service capacity.

The percentage of those who had heard about Khushi clinics significantly increased from Round 1 to Round 
Table 2 Service capacity under the Kavach project

\begin{tabular}{|c|c|c|c|}
\hline $\begin{array}{l}\text { Service } \\
\text { capacity }\end{array}$ & Indicators & $\begin{array}{l}\text { Round I } \\
(2007)\end{array}$ & $\begin{array}{l}\text { Round } 2 \\
(2009)\end{array}$ \\
\hline $\begin{array}{l}\text { Targeted } \\
\text { beneficiaries }\end{array}$ & Estimated number of truckers & 295,000 & 285,000 \\
\hline Infrastructure & Number of sites & 17 & 12 \\
\hline $\begin{array}{l}\text { Average number } \\
\text { of footfalls }\end{array}$ & $\begin{array}{l}\text { Average number of footfalls in } \\
\text { the year }\end{array}$ & $|9,17|$ & 21,368 \\
\hline Provision & $\begin{array}{l}\text { The number of condoms } \\
\text { socially marketed }\end{array}$ & I,306,837 & $1,959,525$ \\
\hline $\begin{array}{l}\text { Effective } \\
\text { indicator }\end{array}$ & $\begin{array}{l}\text { Sites per } 100,000 \\
\text { beneficiaries }\end{array}$ & 6 & 4 \\
\hline $\begin{array}{l}\text { Effective } \\
\text { indicator }\end{array}$ & $\begin{array}{l}\text { Condoms distributed per } \\
\text { thousand beneficiaries }\end{array}$ & 4,430 & 6,876 \\
\hline
\end{tabular}

Notes: Adapted from Avahan CMIS Data. FHI 360:V6. Available from: http://dx.doi. org/ $0.7910 / D V N / 24631 .{ }^{34}$

2 (46.1\% vs 53.8\%, respectively; $\left.\chi^{2}, 24.22 ; P<0.001\right)$. However, the percentage of those who had seen the logo of the Khushi clinic diminished $\left(58.5 \%\right.$ vs $45.4 \% ; \chi^{2}, 74.07$, respectively; $P<0.001)$. By and large, the percentage of those who had either heard of or seen the logo significantly diminished between the two rounds $(60.9 \%$ vs $54.6 \%$, respectively; $\left.\chi^{2}, 16.467 ; P<0.001\right)$. This indicator describes the accessibility coverage in both rounds of analysis.

The percentage of LDTDs who were associated with the Khushi clinic for more than or equal to 6 months had increased between Round 1 and Round 2 (13.8\% vs 50.6\%, respectively; $\left.\chi^{2}, 645.458 ; P<0.001\right)$. Association with a Khushi clinic indicates acceptability coverage among LDTDs. Here, availability, accessibility, and acceptability coverage define the potential coverage, whereas contact and effectiveness coverage are associated with actual coverage.

Contact is characterized as a visit to the Khushi clinic for any reason (a visit to the doctor, to seek care for general ailments, and/or to seek advice/care for an STI). The percentage of individuals who visited Khushi clinics for any purpose significantly increased between Round 1 and Round 2 (12.7\% vs $22.3 \%$, respectively; $\left.\chi^{2}, 65.521 ; P<0.001\right)$. This highlights the contact coverage under the analytical frame of analysis.

As discussed, for effectiveness coverage, two separate measures were used: 1) preventive and 2) curative coverage. Preventive needs are the essential or intrinsic needs, and are controlled by demographic factors. In contrast, curative needs are care-oriented and controlled by demographic and epidemiological aspects. Findings show that percentage of LDTDs who utilized any important preventive service (eg, received condoms or counseling) significantly increased between Rounds 1 and 2 (11.5\% vs 22.4\%, respectively; $\chi^{2}, 85.711$;
$P<0.001)$. This result highlighted prevention-oriented effectiveness coverage. Similarly, the percentage of those who received advice/medicine from the Khushi clinic for any STI significantly increased from Round 1 to $2(0.4 \%$ vs $1.4 \%$, respectively; $\left.\chi^{2}, 10.421 ; P=0.002\right)$. This result defines care-oriented effectiveness coverage. Table 3 summarizes the results of health care coverage under the Kavach intervention.

Likewise, a route-specific analysis of health care coverage shows route-specific differentials in health care coverage between the two rounds of the IBBA-NH survey. Accessibility coverage significantly increased in the NW corridor between the two rounds of the IBBA-NH (49.2\% vs $62.5 \%$, respectively; $\left.\chi^{2}, 18.73 ; P<0.001\right)$. In other corridors, accessibility coverage significantly decreased between the two rounds. Acceptability coverage significantly increased in all national highway corridors. However, the SE corridor recorded the least significant increases between the two rounds $(9.6 \%$ vs $20.1 \%$, respectively). Contact coverage increased significantly in the NW corridor between Round 1 and Round 2 (10.5\% vs 30.4\%, respectively; $\chi^{2}, 63.30$; $P<0.001)$. However, no significant change was seen in other corridors. Effectiveness coverage (preventive or curative) significantly increased in the NE corridor (11.5\% vs $25.0 \%$, respectively; $\left.\chi^{2}, 31.08 ; P<0.001\right)$ and the NW corridor (10.5\% vs $29.3 \%$, respectively; $\chi^{2}<57.47 ; P<0.001$ ). Table 4 shows the route-specific health care coverage under the Kavach project.

The Tanahashi framework permits variation and flexibility in the definition and estimation of coverage. ${ }^{28} \mathrm{~A}$ specific subgroup of the total target population can also be chosen for estimation as the denominator in different coverage ratios. Resulting coverage measurements highlight an alternate aspect of interaction between the service and the populace. This may be called "specific coverage". The actual coverage among people with adequate accessibility to the service can be considered to measure provision-specific coverage. Here, total number of LDTDs in each round - those who had either heard about the Khushi clinic or seen the logo of the Khushi clinic - was taken as the denominator to estimate specific coverage. Table 5 highlights the provision-specific coverage based on adequate accessibility.

Considering provision-specific coverage, acceptability to LDTDs significantly increased between Rounds 1 and 2 (22.6\% to $\left.92.8 \% ; \chi^{2}, 1193.365 ; P<0.001\right)$ among LDTDs who had heard of/seen the logo of the Khushi clinic. In a like manner, among LDTDs who accepted the services, contact coverage significantly increased $(20.9 \%$ to $40.8 \%$; $P<0.001)$. 
Table 3 Evaluation of health care coverage among truckers under the Kavach project, IBBA-NH (Rounds I and 2)

\begin{tabular}{|c|c|c|c|c|}
\hline \multirow[t]{2}{*}{ Type of access } & \multirow[t]{2}{*}{ Indicators } & \multicolumn{3}{|c|}{ IBBA-NH survey } \\
\hline & & $\begin{array}{l}\text { Round I } \\
(n=2,066)\end{array}$ & $\begin{array}{l}\text { Round } 2 \\
(n=2,085)\end{array}$ & $\begin{array}{l}\text { Sig } \\
(P \text {-value })^{\mathrm{a}}\end{array}$ \\
\hline Availability coverage & Service capacity & $100.0 \%$ & $100.0 \%$ & $*$ \\
\hline Accessibility & \% of total LDTDs interviewed who had heard about Khushi clinic & $46.1 \%$ & $53.8 \%$ & $P<0.001$ \\
\hline \multirow[t]{2}{*}{ coverage } & $\%$ of total LDTDs interviewed who had seen the logo of Khushi clinic & $58.5 \%$ & $45.4 \%$ & $P<0.001$ \\
\hline & $\%$ of the total who had either heard or seen the logo of Khushi clinic & $60.9 \%$ & $54.6 \%$ & $P<0.00$ I \\
\hline $\begin{array}{l}\text { Acceptability } \\
\text { coverage }\end{array}$ & $\begin{array}{l}\% \text { of total LDTDs interviewed who associated with the Khushi clinic } \\
\text { (those who are aware about the Khushi clinics for more than or equal to } 6 \text { months) }\end{array}$ & $13.8 \%$ & $50.6 \%$ & $P<0.001$ \\
\hline \multirow[t]{4}{*}{ Contact coverage } & $\%$ of total LDTDs who visited Khushi clinic in the year prior to the survey & $12.6 \%$ & $22.1 \%$ & $P<0.001$ \\
\hline & $\begin{array}{l}\text { \% of total LDTDs who visited Khushi clinic in the year prior to the survey for } \\
\text { STI-related ailments }\end{array}$ & $0.8 \%$ & $2.4 \%$ & $P<0.001$ \\
\hline & \% of total LDTDs who visited Khushi clinic last year for general ailments & $10.8 \%$ & $21.5 \%$ & $P<0.001$ \\
\hline & $\%$ of total LDTDs visiting Khushi clinic for any purpose & $12.7 \%$ & $22.3 \%$ & $P<0.001$ \\
\hline Effectiveness & $\%$ of total LDTDs who received a health card & $9.9 \%$ & $7.3 \%$ & $P=0.003$ \\
\hline coverage & $\%$ of total LDTDs who received condoms & $5.5 \%$ & $12.3 \%$ & $P<0.001$ \\
\hline \multirow[t]{4}{*}{ (preventive) } & $\%$ of total LDTDs who received counseling & $10.7 \%$ & $20.0 \%$ & $P<0.001$ \\
\hline & $\%$ of total LDTDs who received referral from Khushi clinic to other health facilities & $0.8 \%$ & $3.3 \%$ & $P<0.001$ \\
\hline & $\%$ of total LDTDs who attended a meeting/took part in other activities & $3.6 \%$ & $7.4 \%$ & $P<0.00$ I \\
\hline & $\%$ of total LDTDs receiving any important preventive services (condoms or counseling) & $11.5 \%$ & $22.3 \%$ & $P<0.001$ \\
\hline Effectiveness & $\%$ of total LDTDs who sought advice/medicine at Khushi clinic & $0.4 \%$ & $1.4 \%$ & $P=0.002$ \\
\hline coverage (curative) & Effectiveness coverage for any purpose (important preventive or curative coverage) & $11.5 \%$ & $22.4 \%$ & $P<0.001$ \\
\hline
\end{tabular}

Note: a ${ }^{P}$-value is estimated based on Pearson's chi-square test. *Statistical significance is not estimated for this category.

Abbreviations: IBBA-NH, Integrated Behavioural and Biological Assessment, National Highway; LDTDs, long-distance truckers; sig, significance; STI, sexually transmitted infection.

Prevention- and care-oriented effectiveness coverage among LDTDs who had access to the service also increased considerably $\left(18.9 \%\right.$ to $40.8 \% ; \chi^{2}, 111.645 ; P<0.001$, and $0.7 \%$ to $2.5 \% ; \chi^{2}, 12.804 ; P<0.001$, respectively).

\section{Discussion}

The analysis highlights that there is a significant difference in various indicators of service coverage between the two rounds of the IBBA-NH survey. A detailed analysis of the shape of the operation/coverage curve (the locus of different points of various stages of health care coverage) facilitates in identifying issues related to the service delivery at different stages of health care coverage.

Tanahashi ${ }^{28}$ defined these stages/this coverage in such a way that there exists a certain gap between them. A large gap between adjacent pairs of coverage measures shows that, for a proportion of the target population, service provisioning is not meeting their needs. For example, all those who have access to service have not accepted the service, and all those who have accepted the service have not utilized the service. The large differences exhibit the issues in service provision to LDTDs, and show a sharp shift in the operation/coverage curve to the left. Figure 1A and B highlight the shape of the operation/coverage curve.

Figure 1 shows that the coverage curve in Round 2 shifts sharply to the left when compared with Round 1 from availability to accessibility coverage portion. Tanahashi described this sharp shift as the result of inefficient allocation and use of resources and facilities. ${ }^{28}$ However, the intervention is better accepted in Round 2 among LDTDs than in Round 1. A sharp shift in the coverage curve in Round 1 from accessibility to acceptability coverage portion shows the issues related to acceptability of service due to poor acknowledgement of the service among LDTDs, ie, more LDTDs were not going to Khushi clinics in Round 1. These sharp shifts highlight difficulties in the service provision; however, these shifts do not underline the components responsible for the poor coverage. Comprehensive understanding of health services and conditions of the target population is needed to examine the components responsible for poor coverage. Multiple factors play a significant role in access to health care. These factors are identified as demand- and supply-side components/factors. As the analysis highlights the issues of accessibility and acceptability coverage, these barriers are illustrated as the demand- and/or supply-side factors. ${ }^{35,36}$ Demand-side factors influence ability to use the service. The geographical location of a service plays a crucial role in accessing the service; all the same, comprehensive knowledge and awareness about services can influence accessibility considerably. Supplyside factors are inbuilt into the system and decide service uptake. They may be identified with managerial shortcomings or inefficient allocation of resources. Various demand- and 


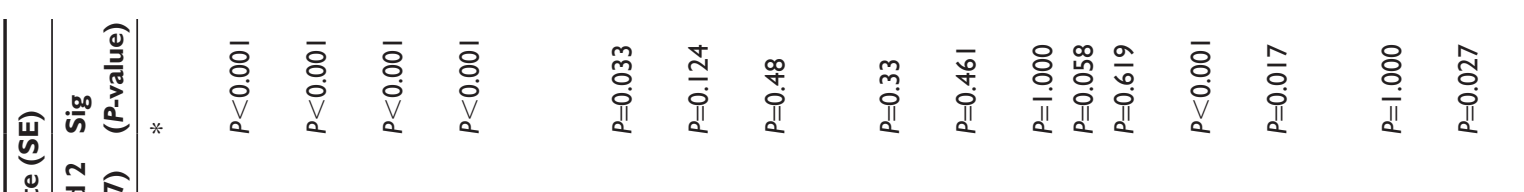

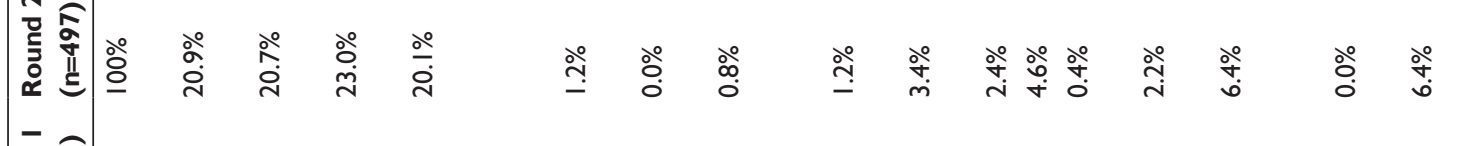

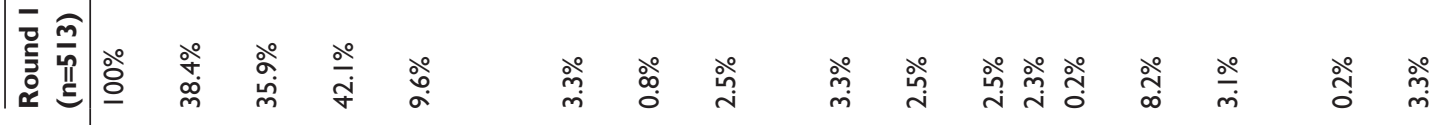

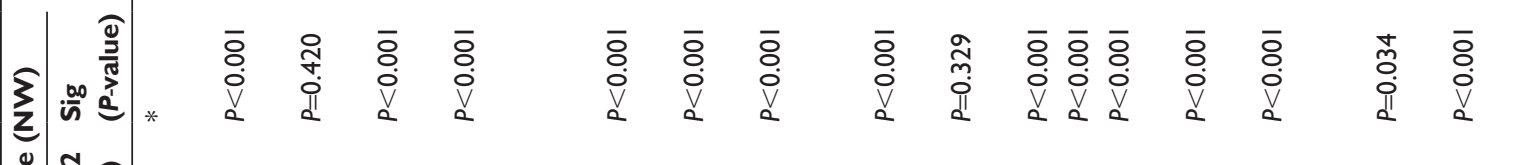

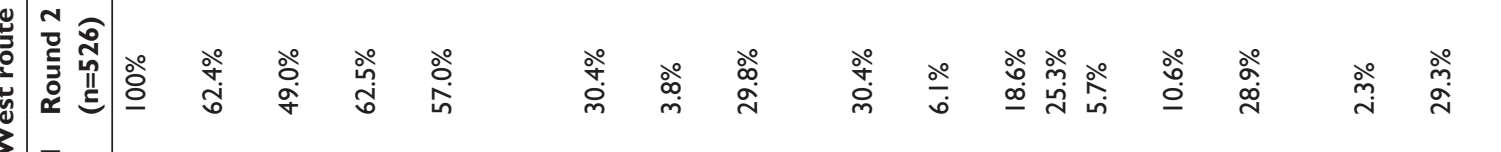

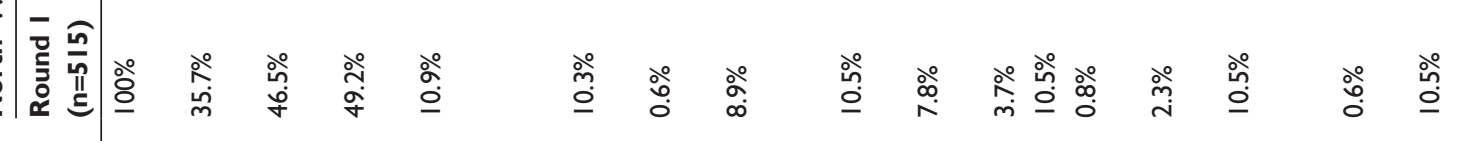

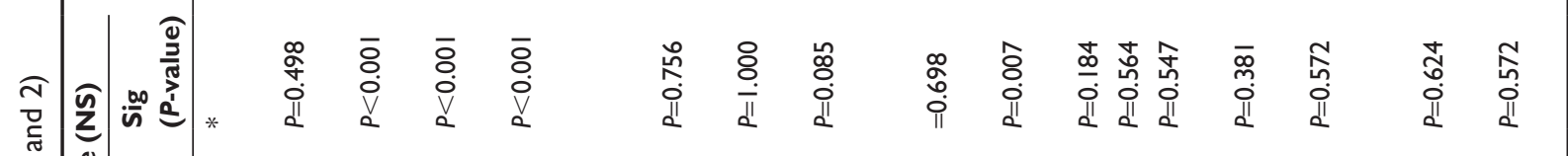

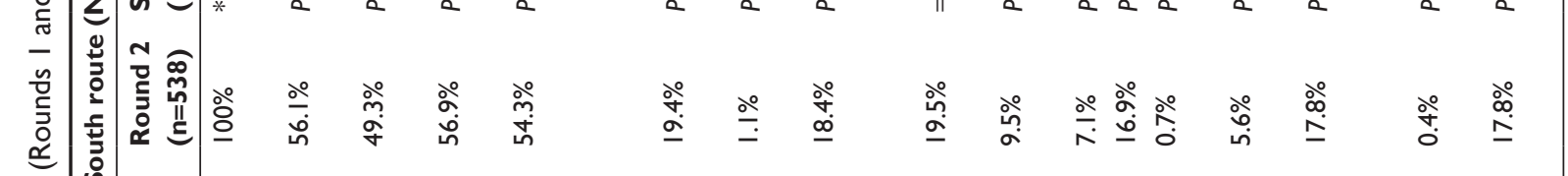

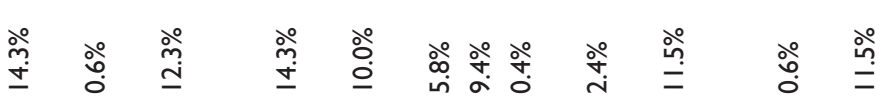

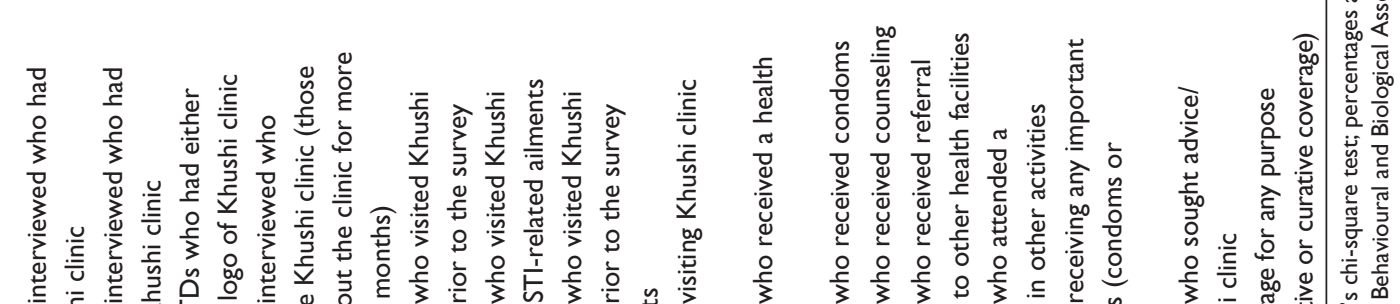

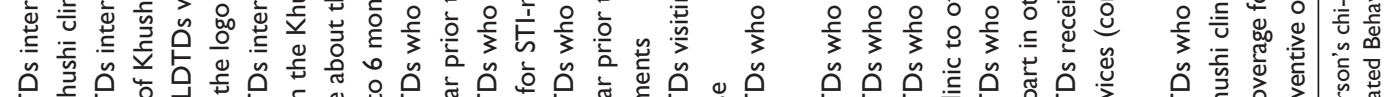

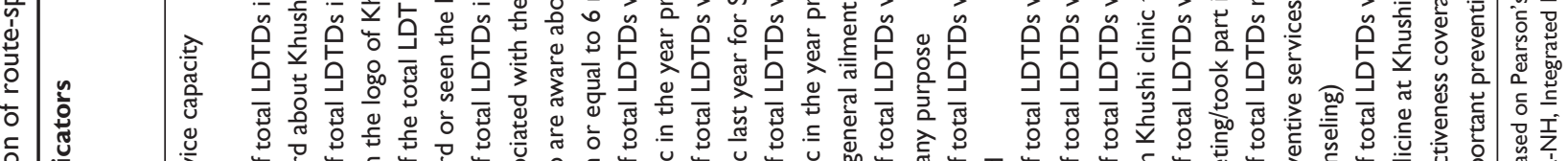

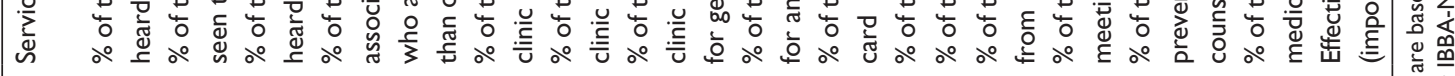


Table 5 Evaluation of provision-specific coverage under the Kavach project, IBBA-NH (Rounds I and 2)

\begin{tabular}{|c|c|c|c|c|}
\hline \multirow{2}{*}{$\begin{array}{l}\text { Type of } \\
\text { access }\end{array}$} & \multirow[t]{2}{*}{ Indicators } & \multicolumn{3}{|c|}{ IBBA-NH survey } \\
\hline & & $\begin{array}{l}\text { Round I } \\
(n=I, 258)\end{array}$ & $\begin{array}{l}\text { Round } 2 \\
(n=948)\end{array}$ & $\begin{array}{l}\text { Sig } \\
(P \text {-value })^{a}\end{array}$ \\
\hline $\begin{array}{l}\text { Acceptability } \\
\text { coverage }\end{array}$ & $\begin{array}{l}\text { \% of LDTDs who had either heard of or seen the logo in Khushi clinic and were } \\
\text { associated with it (those who are aware about the clinic for more than or equal } \\
\text { to } 6 \text { months) }\end{array}$ & $22.6 \%$ & $92.8 \%$ & $<0.001$ \\
\hline \multirow[t]{4}{*}{$\begin{array}{l}\text { Contact } \\
\text { coverage }\end{array}$} & $\begin{array}{l}\% \text { of LDTDs who had either heard of or seen the logo in Khushi clinic and visited } \\
\text { Khushi clinic in the year prior to the survey }\end{array}$ & $20.7 \%$ & $40.5 \%$ & $<0.001$ \\
\hline & $\begin{array}{l}\% \text { of LDTDs who had either heard of or seen the logo in Khushi clinic and visited } \\
\text { Khushi clinic in the year prior to the survey for STI-related ailments }\end{array}$ & $1.3 \%$ & $4.5 \%$ & $<0.001$ \\
\hline & $\begin{array}{l}\% \text { of LDTDs who had either heard of or seen the logo in Khushi clinic and visited } \\
\text { Khushi clinic in the year prior to the survey for general ailments }\end{array}$ & $17.8 \%$ & $39.4 \%$ & $<0.001$ \\
\hline & $\begin{array}{l}\% \text { of LDTDs who had either heard of or seen the logo in Khushi clinic and visited } \\
\text { Khushi clinic for any purpose }\end{array}$ & $20.9 \%$ & $40.8 \%$ & $<0.001$ \\
\hline $\begin{array}{l}\text { Effectiveness } \\
\text { coverage }\end{array}$ & $\begin{array}{l}\% \text { of LDTDs who had either heard of or seen the logo in Khushi clinic and received } \\
\text { a health card }\end{array}$ & $16.2 \%$ & $13.3 \%$ & $<0.05$ \\
\hline \multirow[t]{5}{*}{ (preventive) } & $\%$ of LDTDs who had either heard of or seen the logo in Khushi clinic & $9.0 \%$ & $22.5 \%$ & $<0.001$ \\
\hline & $\begin{array}{l}\% \text { of LDTDs who had either heard of or seen the logo in Khushi clinic and received } \\
\text { counseling }\end{array}$ & $17.5 \%$ & $36.5 \%$ & $<0.001$ \\
\hline & $\begin{array}{l}\% \text { of LDTDs who had either heard of or seen the logo in Khushi clinic and received } \\
\text { a referral from Khushi clinic to other health facilities }\end{array}$ & $1.4 \%$ & $6.1 \%$ & $<0.001$ \\
\hline & $\begin{array}{l}\% \text { of LDTDs who had either heard of or seen the logo in Khushi clinic and } \\
\text { attended a meeting/took part in other activities }\end{array}$ & $5.9 \%$ & $13.6 \%$ & $<0.001$ \\
\hline & $\begin{array}{l}\% \text { of LDTDs who had either heard of or seen the logo in Khushi clinic and received } \\
\text { any important preventive services (condoms or counseling) }\end{array}$ & $18.9 \%$ & $40.8 \%$ & $<0.001$ \\
\hline $\begin{array}{l}\text { Effectiveness } \\
\text { coverage }\end{array}$ & $\begin{array}{l}\% \text { of LDTDs who had either heard of or seen the logo in Khushi clinic and sought } \\
\text { advice/medicine at Khushi clinic }\end{array}$ & $0.7 \%$ & $2.5 \%$ & $<0.001$ \\
\hline (curative) & Effectiveness coverage for any purpose (important preventive or curative coverage) & $18.9 \%$ & $41.8 \%$ & $<0.001$ \\
\hline
\end{tabular}

Notes: aP-values are estimated based on Pearson's chi-square test.

Abbreviations: IBBA-NH, Integrated Behavioural and Biological Assessment, National Highway; LDTDs, long-distance truckers; sig, significance; STI, sexually transmitted infection.

supply-side interventions (monetary and non-monetary) can address these barriers/issues and significantly increase access to health care. Under the Kavach project, various interventions were initiated to provide access to care.

Low acceptability of the service in Round 1 shows the issues regarding acceptability coverage. The demand-side factors which may have influenced this may be related to low self-esteem or lack of health consciousness among LDTDs, which increases the challenge of accessing health care. ${ }^{37}$ At the supply side, factors influencing acceptability may relate to awareness generation costs of the service or inability of staff to build a trust association or rapport with the beneficiary. ${ }^{38}$

Coverage curves in both rounds, however, do not reveal issues in effectiveness coverage. This highlights the quality of service provided by the intervention/health care facility, ie, that those who have accepted the services, have utilized them as well. Likewise, in Figure 1B, provision-specific coverage curves reveal that acceptance of service was a major issue in service delivery in Round 1.

To overcome demand- and supply-side obstacles in service provisioning, various interventions may be initiated. These interventions can be monetary and non-monetary. Demand-side (non-monetary) interventions include counseling and provision of information, community participation, and social marketing. ${ }^{39}$ Under HIV prevention interventions, these have been applied to promote condom use and improve treatments for selected STIs. ${ }^{40}$ Measures like peer educators, outreach activities, etc, also attempt to overcome community and cultural preferences and prompt acceptability of services. ${ }^{40} \mathrm{~A}$ study in the past have also cited that a range of preventive interventions implemented through non-professional health workers, and recruitment of them from within the community, reduces many acceptability barriers. ${ }^{41}$ Under the Kavach project, various demand-side (non-monetary) interventions were introduced, eg, peer educators, counseling, and social marketing of condoms, etc, which were attempts to fill the gaps in health care coverage. Demand-side monetary interventions were not introduced under the Kavach project. However, free consultation for healthrelated issues (general ailments, STIs, and HIV infection) and referrals may be considered incentives that may have facilitated acceptability and contact (by increasing affordability). The multi-media communication plan under the Kavach program has resulted in a doubling of monthly reach across the program (in terms of monthly contacts through peer-led interpersonal 

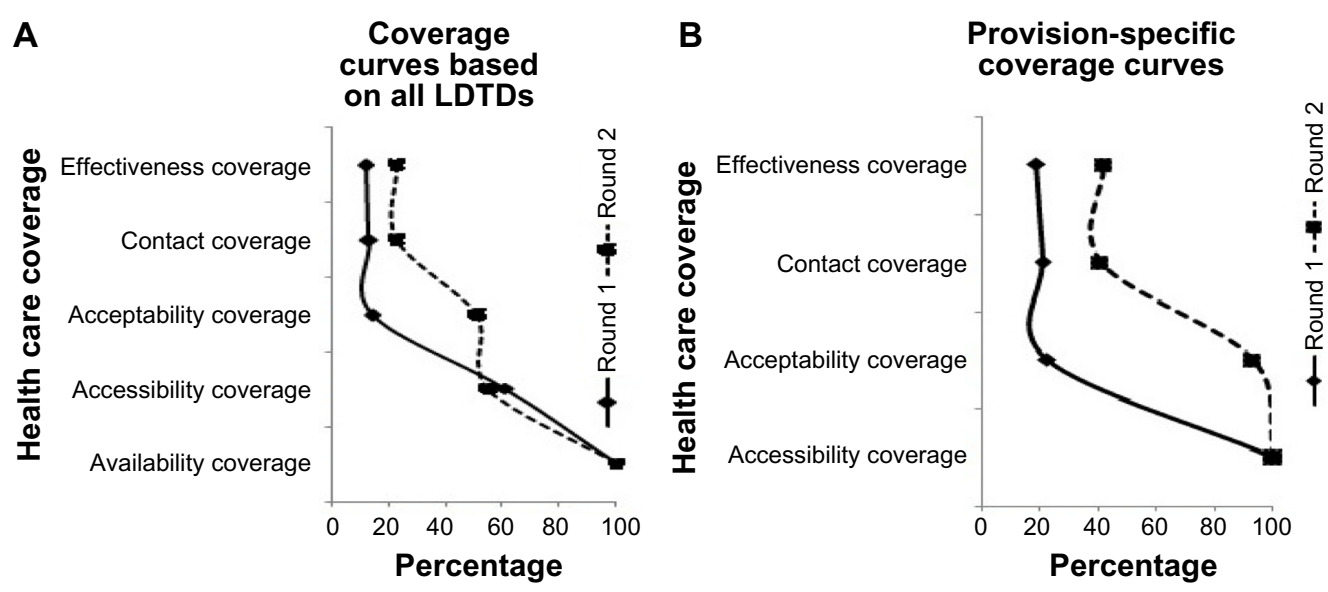

Figure I Coverage curves for the provision of health care to LDTDs through the Kavach project. Coverage curves based on all LDTDs (A), and provision-specific coverage curves (B).

Abbreviation: LDTDs, long-distance truckers.

communication and participation in mid-media activities). ${ }^{26}$ Recall of the Khushi brand also significantly increased among the targeted LDTDs, resulting in significant uptake of services by Round 2 survey time. ${ }^{26}$

Similarly, supply-side non-monetary interventions are identified, with provisioning of essential services at health facilities (preventive and curative care) at cost. These interventions address availability and affordability, to an extent. Provision of preventive care services meets the expectations of individuals. If the services are provided at the facility, they are mostly used by individuals (acceptability). Provision of improved access to services has resulted in uptake of clinical services by a factor of 2.5 across 17 intervention sites. ${ }^{26}$ Similarly, regulation of the health and non-health sectors of public-private service provision may address issues related to affordability. The provision of integrated outreach activities tackles the issue related to accessibility, although the range may be limited. The provision of culturally sensitive health care can be improved through specific courses or by employing members of the same ethnic groups (acceptability). Improved management, and system-inbuilt supervision and feedback mechanisms, possibly provide the best guarantee as they can effectively address all four dimensions related to access barriers, and amend each associated aspect, as long as sufficient resources are available. Management can thoroughly deal with issues identified with human resources, finances, and service organization and delivery. Furthermore, there are ranges of monetary interventions which can enhance access to health care and reduce barriers.

The Kavach project, with a mix of different demand-side and supply-side interventions, provided access to health care coverage. The analysis in this paper reflects the gaps in the health care coverage under the intervention. However, all these interventions under the project were not able to provide a solution for all access-related issues. This gives an opportunity for policy makers and implementing agencies to improve access considerably by taking into account the lessons learnt from various initiatives under the project. As suggested by O'Donnell ${ }^{36}$ and De Brouwere et al, ${ }^{42}$ various demand-side and supply-side barriers must be addressed to realize the optimal impact of any intervention. Adequate selection of interventions will facilitate the access to health care given the political, cultural and geographical environment and historical development of the health sector.

The findings of this paper should be read with certain caveats. Definitions of coverage and identification of corresponding indicators were confined to the questions asked in the IBBA-NH survey. Wherever possible, different indicators are taken as a close proxy to accurate indicators. This may have resulted in some aspects of coverage being inadequately explored.

\section{Conclusion}

This paper emphasizes the need for further studies to assess contextual factors that influence the effectiveness and efficiency of interventions designed to address access barriers and to identify what combination of interventions may generate the best possible outcome. It comments on the gaps in accessibility and acceptability of health care coverage. The analysis based on the Tanahashi framework of evaluation of health care coverage can be used to identify the gaps in different stages of service delivery, and then can be used to analyze the constraining factors, taking into account interventions under consideration. This may facilitate the 
better implementation of any intervention and uptake of other interventions of comparable nature.

\section{Acknowledgments}

This paper was written as a part of the Knowledge Network Project of the Population Council, as a grantee from the BMGF through Avahan, its India AIDS Initiative. The authors would like to thank Professor Indrani Gupta, Institute of Economic Growth, New Delhi, India for giving her invaluable comments on the earlier draft of this paper. However, the views expressed in this paper are of the author(s) alone and do not necessarily reflect the official policy or position of the BMGF and Avahan.

\section{Author contributions}

All authors contributed toward data analysis, drafting and revising the paper and agree to be accountable for all aspects of the work.

\section{Disclosure}

The authors report no conflicts of interest, financial or otherwise, in this work.

\section{References}

1. The World Bank. Transport Against HIV/AIDS: Synthesis of Experience and Best Practice Guidelines. Washington, DC: The World Bank; 2009. Available from: http://siteresources.worldbank.org/INTTRANSPORT/ Resources/336291-1227561426235/5611053-1229359963828/tp-25HIV-AIDS.pdf. Accessed January 3, 2015.

2. Chandrasekaran P, Dallabetta G, Loo V, Rao S, Gayle H, Alexander A. Containing HIV/AIDS in India: the unfinished agenda. Lancet Infect Dis. 2006;6(8):508-521

3. Rao KS, Pilli RD, Rao AS, Chalam PS. Sexual lifestyle of long distance lorry drivers in India: questionnaire survey. BMJ. 1999;318(7177): $162-163$.

4. Hudson CP. AIDS in rural Africa: a paradigm for HIV-1 prevention. Int J STD AIDS. 1996;7(4):236-243.

5. Rao VT, Mahapatra B, Juneja S, Singh IR. Evaluating the McDonald's business model for HIV prevention among truckers to improve program coverage and service utilization in India, 2004-2010. HIV AIDS (Auckl). 2013;5:51-60.

6. Pandey A, Mishra RM, Sahu D, et al. Heading towards the Safer Highways: an assessment of the Avahan prevention programme among long distance truck drivers in India. BMC Public Health. 2011;11(Suppl 6):S15.

7. Sanjeev K, S K G, S K B. A study of knowledge, sexual behaviour and practices regarding HIV/AIDS among long distance truck drivers. Indian J Public Health. 2009;53(4):243-245.

8. Cornman DH, Schmiege SJ, Bryan A, Benziger TJ, Fisher JD. An information-motivation-behavioral skills (IMB) model-based HIV prevention intervention for truck drivers in India. Soc Sci Med. 2007;64(8):1572-1584.

9. Singh YN, Malaviya AN. Long distance truck drivers in India: HIV infection and their possible role in disseminating HIV into rural areas Int J STD AIDS. 1994;5(2):137-138.

10. Bhalla S, Chandwani H, Singh D, Somasundaram C, Rasania SK, Singh S. Knowledge about HIV/AIDS among senior secondary school students in Jamnagar, Gujarat. Health Popul Perspect Issues. 2005;28: 178-188.
11. Mohamed A, Pacca JC. CAP study on truck drivers in Maputo/ Mozambique: prevention roadblocks in a group passing through high prevalence zones. International Conferences on AIDS; Jul 7-12, 2002; 14, abstract no. D11169.

12. Sohail A. Sexual behaviour among truck drivers in Pakistan. Culture, Health and Sexuality. 2002;4(2):191-206.

13. International Labour Organisation. Report and analysis of "A Truck Driver's Life: Working Conditions and Sexual Health". HIV and Long-distance Transport in Paraguay. Santiago: International Labour Organisation; http://www.ilo.org/wcmsp5/groups/public/@ed_protect/@protrav/@ilo_aids/documents/publication/wcms_184517.pdf. 2012. Accessed January 3, 2015.

14. McCree DH, Cosgrove S, Stratford D, et al. Sexual and drug use risk behaviors of long-haul truck drivers and their commercial sex contacts in New Mexico. Public Health Rep. 2010;125(1):52-60.

15. Prem Kumar SG, Kumar GA, Poluru R, et al. Contact with HIV prevention programmes and willingness for new interventions among truckers in India. Indian J Med Res. 2013;137(6):1061-1071.

16. Pal K. "Fearless": Improving Sexual and Reproductive Health of Female Sex Workers. India HIV/AIDS Alliance. http://www.allianceindia.org/ fearless-improving-sexual-reproductive-health-of-female-sex-workers/. Accessed Feb 1, 2014.

17. Chakrapani V, Newman PA, Shunmugam M, Kurian AK, Dubrow R. Barriers to free antiretroviral treatment access for female sex workers in Chennai, India. AIDS Patient Care STDS. 2009;23(11):973-980.

18. Pulerwitz J, Michaelis AP, Lippman SA, Chinaglia M, Díaz J. HIVrelated stigma, service utilization, and status disclosure among truck drivers crossing the Southern borders in Brazil. AIDS Care. 2008;20(7): 764-770.

19. Saggurti N, Mishra RM, Proddutoor L, et al. Community collectivization and its association with consistent condom use and STI treatmentseeking behaviors among female sex workers and high-risk men who have sex with men/transgenders in Andhra Pradesh, India. AIDS Care. 2013;25(Suppl 1):S55-S66.

20. Baqui AH, Rosecrans AM, Williams EK, et al. NGO facilitation of a government community-based maternal and neonatal health programme in rural India: improvements in equity. Health Policy Plan. 2008;23(4): 234-243.

21. Ubaidullah M. Social vaccine for HIV prevention: a study on truck drivers in South India. Soc Work Health Care.. 2004;39(3-4):399-414.

22. National AIDS Control Organisation (NACO). Targeted Interventions Under NACP III. Operational Guidelines. New Delhi: NACO, Ministry of Health \& Family Welfare, Government of India; 2007. Available from: http://www.naco.gov.in/upload/Publication/ NGOs\%20and\%20targetted\%20Intervations/NACP-III.pdf. Accessed January 3, 2015.

23. National AIDS Control Organisation (NACO). Annual HIV Sentinel Surveillance Country Report 2006. New Delhi: National Institute of Health \& Famliy Welfare, NACO, Ministry of Health \& Family Welfare; 2007. Available from: http://naco.gov.in/upload/NACO $\% 20 \mathrm{PDF} /$ HIV\%20Sentinel\%20Surveillance\%202006_India\%20Country\%20 Report.pdf. Accessed January 3, 2015.

24. Rao A, Nag M, Mishra K, Dey A. Sexual behaviour pattern of truck drivers and their helpers in relation to female sex workers. Ind J Soc Work. 1994;55(4):603-615.

25. National AIDS Control Organisation (NACO). Annual HIV Sentinel Surveillance: Country Report 2008-09. New Delhi: National Institute of Health \& Famliy Welfare, NACO, Ministry of Health \& Family Welfare; 2011. Available from: http://naco.gov.in/upload/Surveillance/ Reports\%20\&\%20Publication/HIV\%20Sentinel\%20Surveillance $\% 20$ India\%20Country\%20Report,\%202008-09.pdf. Accessed January 3, 2015.

26. Bill and Melinda Gates Foundation. Off the Beaten Track: Avahan's Experience in the Business of Prevention among India's Long-Distance Truckers. New Delhi: Bill and Melinda Gates Foundation; 2008. Available from: https://docs.gatesfoundation.org/Documents/Avahan_ OffTheBeatenTrack.pdf. Accessed January 3, 2015. 
27. Gelmon LJ, Singh K, Singh P, Bhattacharjee P, Moses S, Costigan A, Blanchard J. Sexual Networking and HIV Risk in Migrant Workers in India. In: XVIth International AIDS Conference, Toronto, Canada, August 2006; Abstract MOAC0304, Abstract volume 1.

28. Tanahashi T. Health service coverage and its evaluation. Bul WHO. 1978;56(2):295-303.

29. Maru DS, Khakha DC, Tahir M, Basu S, Sharma SK. Poor follow-up rates at a self-pay northern Indian tertiary AIDS clinic.. Int J Equity Health. 2007;6:14.

30. World Bank. Corporate Responses to HIV/AIDS: Case Studies from India. Washington, DC: The World Bank; 2007.

31. National Institute of Medical Science. Integrated Behavioural and Biological Assessment - National Highways. New Delhi, India: National Institute of Medical Statistics, Indian Council of Medical Research, Department of Health Research, Ministry of Health \& Family Welfare, Government of India; 2011. Available from: http:/www.ibbainfo.in/ keydoc/reports/SR_NH.pdf. Accessed January 3, 2015.

32. McIlfatrick S, Hasson F, McLaughlin D, et al. Public awareness and attitudes toward palliative care in Northern Ireland. BMC Palliat Care. 2013;12(1):34.

33. Krishbaun M, Carey I, Purcell B, Nash S. Talking About Dying and Death: A Focus Group Study to Explore a Local Community Perspective. Nursing Reports. 2011;1(e8):29-34.

34. Avahan CMIS Data [database on the Internet]. FHI 360:V6. Available from: http://dx.doi.org/10.7910/DVN/24631. Accessed February 4, 2015
35. Ensor T, Cooper S. Overcoming barriers to health service access: influencing the demand side. Health Policy and Planning. Mar 2004; 19(2):69-79.

36. O'Donnell O. Access to health care in developing countries: breaking down demand side barriers. Cadernos de saude publica. 2007; 23(12):2820-2834.

37. Paphassarang C, Philavong K, Boupha B, Blas E. Equity, privatization and cost recovery in urban health care: the case of Lao PDR. Health Policy Plan. 2002;17(Suppl):72-84.

38. Ozawa S, Walker DG. Trust in the context of community-based health insurance schemes in Cambodia: villagers' trust in health insurers. Adv Health Econ Health Serv Res. 2009;21:107-132.

39. Price N. The performance of social marketing in reaching the poor and vulnerable in AIDS control programmes. Health Policy Plan. 2001;16(3):231-239.

40. Jacobs B, Kambugu FS, Whitworth JA, et al. Social marketing of prepackaged treatment for men with urethral discharge (Clear Seven) in Uganda. Int J STD AIDS. 2003;14(3):216-221.

41. Haines A, Sanders D, Lehmann U, et al. Achieving child survival goals: potential contribution of community health workers. Lancet. 2007; 369(9579):2121-2131.

42. De Brouwere V, Richard F, Witter S. Access to maternal and perinatal health services: lessons from successful and less successful examples of improving access to safe delivery and care of the newborn. Trop Med Int Health. 2010;15(8):901-909.
HIV/AIDS - Research and Palliative Care

\section{Publish your work in this journal}

HIV/AIDS - Research and Palliative Care is an international, peerreviewed open-access journal focusing on advances in research in HIV, its clinical progression and management options including antiviral treatment, palliative care and public healthcare policies to control viral spread. The journal welcomes original research, basic science,

\section{Dovepress}

clinical \& epidemiological studies, reviews \& evaluations, expert opinion \& commentary, case reports \& extended reports. The manuscript management system is completely online and includes a very quick and fair peer-review system. Visit http://www.dovepress.com/ testimonials.php to read real quotes from published authors. 